\title{
The Rise and Rise of Digital Gluttony
}

\author{
$\Rightarrow \quad$ Neville Holmes, University of Tasmania
}

\section{The computing profession is responsible for the proper use of digital technology.}

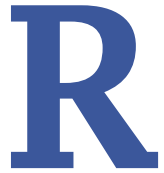

ecently I went to a lecture on "The Cyborg Experiments" delivered by Kevin Warwick, who may well be the first cyborg (tinyurl. com/cgt8ns). The experiments described and showed the coupling of computers to biological neural systems, and to watch them was fascinating.

To develop and use new technology that compensates for human malfunction is clearly promising and worthwhile. However, the possibility of using it to augment normal human functioning is a topic that needs considered debate, not least within the computing profession. Such augmentation would be vastly more powerful and potentially dangerous than that developed by present technology (The Profession, Aug. 2009, pp. 116, 113-115).

Such thoughts added another aspect to misgivings I have about aspects of the huge and largely unbridled expansion of digital technology. The problems arise from what I have come to think of as digital gluttony, the habitual and unthinking consumption of digital products.

Digital gluttony is an enormous and difficult problem. It's important to realize, though, that its problems arise from the use of digital technology, not from the technology itself. Because the computing profession is responsible for digital technology's proper use, its members must consider digital gluttony and press for measures that reduce its incidence.

Digital gluttony has many interrelated aspects, but simple examples reveal the main ones.

\section{EQUIPMENT GLUTTONY}

To say that digital equipment is proliferating is to understate the matter. Not only are computers being used increasingly, they're being built into increasingly different equipment types.

Developers justify this partly because it makes faster and more capacious devices possible. It also means new models, which in turn can mean more sales and profits. The question then is whether users really need this greater speed or capacity.

Consider the mobile phone. My wife and I each have one, but we only use them to talk to each other when separated or, very rarely, to make voice calls (The Profession, Feb. 2006, pp. 112, 110-111). Yet our mobile phones, the simplest we could find, are enormously more complex than our landline handset and stuffed with features we don't want-such as a video camera. When we do switch on our phones, they often play a few bars of loud music to tell us several messages await us: presumably sales pitches.
A simple mobile phone would have many benefits. It would be easier to make and operate, and it could be cheaper to buy and use. With appropriate chips, it could be designed to minimize transmission load and recognize voices. It could even recognize speech so that a keyboard would be unnecessary and the phone would last longer. It could be made much more affordable for people in thirdworld countries, and so a greater weapon in the fight against poverty (tinyurl.com/621lkq).

This is only an example, but the scenario is relevant to many digital products. While the relatively shortterm benefits of device simplicity are clear for many individual users, the long-term benefits are less obvious but could benefit the world's economy.

A greater turnover of digital products means greater discarding of them into rubbish, so-called e-waste, which is difficult and expensive to recycle and unhealthy to handle. Because digital equipment is built from a complex of substances, many of which are like oil in being a limited resource, even recycling with its inevitable losses won't stop digital manufacture from eventually hitting a brick wall, especially with the accelerating demand from the BRIC (Brazil, Russia, India, and China) nations.

Continued on page 94 


\section{STORAGE GLUTTONY}

My first experience with peripheral data storage involved an IBM 350 RAMAC. It stored 5 million characters, and General Motors Holden used it to store their entire spare parts stock data for all of Australia.

This was the start of a long line of disk drives of increasing capacity. In those days we had a saying when planning a computer installation: data expand to fit the space available. It was our practice to double the customer's estimate of total file size, then double it again.

The amount of data storage available today is enormous, but data still expand to fill it. For example, the Large Hadron Collider is now working again and will produce 15 million Gbytes per year (tinyurl.com/ozxsh), boosting Web caches' popularity (tinyurl.com/y6gwdc).

We had a saying when planning a computer installation: data expand to fit the space available.

With data sticks of polygigabyte capacity on sale in supermarkets, and hard disks around the world connected by the Web, the social and professional implications are complex and ramified.

There are copyright issues galore over data being copied, and privacy issues erupting over the vast collections of data exuding from security cameras. What is perhaps most significant about storage gluttony, however, is the effect on libraries, both public and institutional. Many are coming to seem more like Internet cafés, and search engines are replacing card indexes. There are two problems here.

First, the personal role of the library is disappearing: the conversations and enquiries, the scanning of magazines, the browsing around shelves, the sitting back and thinking while reading a book, and the impulsive borrowing.
Second, the library's authoritative role is also disappearing, replaced by the Web and its search engines. It's disquieting that researchers depend so much on Google and that ordinary people looking for scientific information or medical advice on the Web can be so easily misled (tinyurl.com/ ycl7que).

Another worrying aspect is that research libraries and librarians are paid for by the researchers' employees, whereas Web searches are paid for by advertisers (tinyurl.com/ ycsqluy). Moreover, advertisers and other publicists employ techniques or professionals to coerce search engines to rank their Web pages highly (tinyurl.com/hdmh4).

Of course, search engines are wonderful for everyday queries, such as occur to me when writing an essay such as this. Google just

now revealed that the phrase digital gluttony was in use at least two years ago (tinyurl.com/3a8xtd).

\section{PROGRAM GLUTTONY}

Just as peripheral data storage has grown rapidly in size and speed, so has main storage. One of the earlier computers I programmed, an IBM 1401 , originally had a main store of $1,400,2,000$, or 4,000 6/1-bit characters, although later models of this popular machine could hold up to 16,000 in main storage.

An amusing challenge for new programmers was to have them write a program in machine language that would fit on one card (and thus contain fewer than 81 characters)-for example, to print out successive powers of two. It could fairly easily be done. Today, programs take up a lot more space.

Program gluttony is evident at three levels: individual programs, operating systems, and digital projects. A successful program in an application area will breed bigger and better successors. A notable example is the chess-playing program (tinyurl. com/35djxt). Of course, as a learning tool for novices, as a training tool for professional players, or as an investigatory tool for neuroscientists, the grand modern programs are maybe justified, but I find the idea of contests between human and computer partnerships rather queer (mentioned by Garry Kasparov in Google cache tinyurl.com/y4okn9u, but not in the current version, tinyurl.com/ y9wrlw4)

The best reason for playing most games is for the variety of social interaction, as in duplicate bridge at the local club. Playing a game with a computer isn't usually social at all and often decidedly antisocial. But computer games can suck you in. I remember quite some years ago having to wean myself off Minesweeper. Recently, a South Korean couple let their baby starve to death because they were addicted to bringing up a virtual baby online (tinyurl. com/yftr9k2).

Operating system gluttony has frequently been commented on. One of its chief symptoms is what could well be called feature cancer. Adding features might indeed improve capability but all too often complicates usage to the extent where help facilities don't.

Similarly, big project failure, typically associated with big business and government, is all too common. This is usually primarily a failure of management aided by expensive consultants and review committees who produce inappropriately complex designs.

\section{TRANSMISSION GLUTTONY}

The accelerating use of digital technology on a great variety of equipment linked into digital networks in various ways is certainly 
gluttonous, especially with smart phones, iPads, and the like joining in the feast.

One result, at least for wireless networking, is that increased traffic could well slow down individual transmissions and reduce the capacity (tinyurl.com/ylywybk). The effect will be even greater as very many autonomous devices, such as smart meters of various kinds, come into wireless use, as they are in many countries.

The increasing use of wireless networking is also hazardous to health (weepintitiative.org), especially in the case of smart meters (tinyurl.com/ y3yyo8b).

Gluttony also causes problems at the personal level. With the broadband speed to our house boosted by a factor of more than 10 , we now get files downloaded with very little wait. However, we now don't have enough time to stop the browser downloading and running all those highly aggravating video advertisements. And with facilities such as iAds coming along, such problems will become widespread (tinyurl. com/yeots $2 d$ ). And, with smart phones now commonly being issued to employees, the e-mail gluttony previously confined to the office has spread into personal life.

\section{IMAGE GLUTTONY}

One aspect of digital gluttony passed over so far is the increasing use of digital imagery, especially moving pictures of reality or unreality. This is a large factor in transmission gluttony, but storage gluttony is also fed by the imagery, and program gluttony creates the load of unreal imagery.

It is, however, the social effects of image gluttony that cause most concern. They started with the adoption of broadcast television, and have been steadily increased, especially for children.

Image gluttony supports the enthronement of celebrities as role models, corroding the social values of children and adults alike, but apparently affects disadvantaged children more than privileged ones (tinyurl. com/yzn2dyd).

It seems to me that the image gluttony of videogames is much more dangerous than passive television because it accentuates the sensual side of human culture and drowns the contemplative (The Profession, Nov. 2005). How can it be held that the active and vivid participation in videogames that commit and reward virtual acts of violence, including rape and murder, has no effect on the player's attitudes and values?

This topic is a highly emotional one for many people. To counteract the stress of reading about it, I offer the following double dactyl (tinyurl.com/ ykyk4qh):

Higgledy piggledy,

Digital gluttony

Magnifies hedony,

Minifies thought.

Somewhat like virtual

Frontal lobotomy,

Quasireality's

Sensually fraught.
$\mathrm{T}$ he world faces many problems beyond digital gluttony. For example, daily we must confront challenges presented by climate change, widespread violence, and severe international and intranational inequalities. All these are basically social problems.

The computing profession can play a big part in dealing with such problems, but the issue of digital gluttony poses the greatest responsibility. Primarily a cultural problem, digital technology must be used for developing the benevolent cultural values that will counter digital gluttony. This won't come from augmenting the few people who will be able to afford it.

On a lighter note, I invite readers to submit any double dactyls that they're inspired to compose for the first four kinds of digital gluttony, or even to improve on the fifth. [

Neville Holmes is an honorary research associate at the University of Tasmania's School of Computing and Information Systems. Contact him at neville.holmes@utas.edu.au.

Selected CS articles and columns CD are available for free at http:// ComputingNow.computer.org.

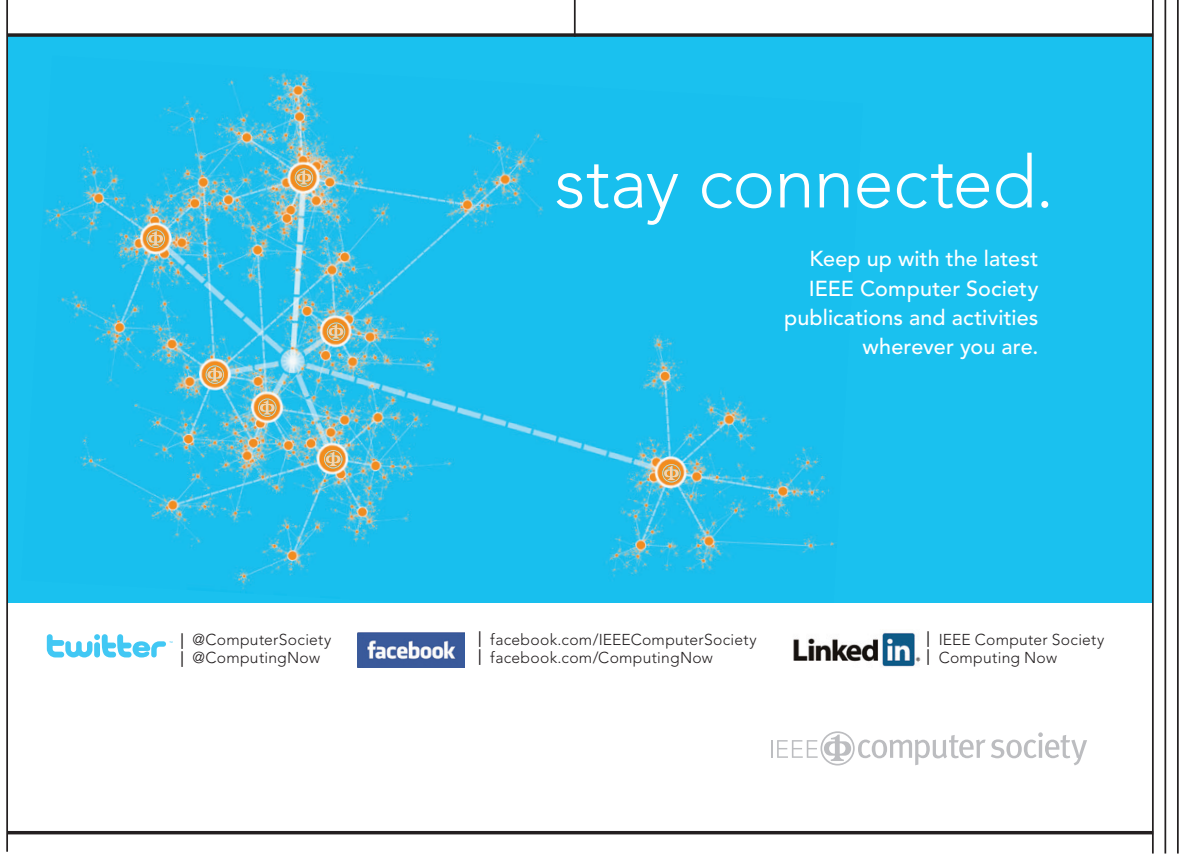

